This item was submitted to Loughborough's Research Repository by the author.

Items in Figshare are protected by copyright, with all rights reserved, unless otherwise indicated.

\title{
Pluripotent stem cell based medicinal products: A case study of process transfer related technical and manufacturing issues [Abstract]
}

\section{PLEASE CITE THE PUBLISHED VERSION}

http://dx.doi.org/10.1016/j.jcyt.2017.02.211

\section{PUBLISHER}

(C) Elsevier

VERSION

AM (Accepted Manuscript)

\section{PUBLISHER STATEMENT}

This work is made available according to the conditions of the Creative Commons Attribution-NonCommercialNoDerivatives 4.0 International (CC BY-NC-ND 4.0) licence. Full details of this licence are available at: https://creativecommons.org/licenses/by-nc-nd/4.0/

\section{LICENCE}

CC BY-NC-ND 4.0

\section{REPOSITORY RECORD}

Sebastian, Sujith, Amit Chandra, Paul C. Hourd, Samantha L. Wilson, Mark J.S. McCall, Nick Medcalf, Robert James Thomas, and David J. Williams. 2019. "Pluripotent Stem Cell Based Medicinal Products: A Case Study of Process Transfer Related Technical and Manufacturing Issues [abstract]”. figshare. https://hdl.handle.net/2134/25090. 
staining and endotoxin were negative in all cases. Validation included the assessment of CD34+ cells stability after a 48h-storage.

Conclusion: Herein we demonstrated the establishment of a feasible, consistent and reproducible bioprocess for safe manufacturing of expanded CD34+ cells for clinical use, opening the way for a Phase I/II clinical trial which is currently recruiting.

\section{9}

THE PERFECT LOGISTIC TRANSPORT METHOD CONCERNING ALL KIND OF CELL THERAPY PRODUCTS

S. Schoeffel-Weiss, K. Schormann, M. Cartellieri

CMT, Cologne, Germany

During the last few years different T-cell therapy products like CTLP (CMVspecific T-lymphocyte precursor cells) or CAR (chimeric antigen receptor) T-cells were further developed, it became increasingly important to find the most suitable transport method for starting, intermediate as well as for final products.

During clinical phase II and III studies GMP facilities as well as hospitals all over the world have to be connected. Beside a perfect logistic supply chain the right transport method and transport material is even more essential.

Ahead of a phase III study we have tested different transport methods in terms of safety, reliability and speed.

On-board transport

Cargo transport

Transport of cryopreserved products

First we put an eye on different transport material—we compared different types of LN2 shippers and on-board transport containers. In a second step we shipped mock products to test the transport under real conditions. Finally we performed during a phase III study on-board transports as well as transports of starting material, CD3 enriched and final products.

The test results showed clearly that the transport material has to be chosen in accordance to the product that has to be transported to avoid foreseeable product damage.

During the mock transports material differences turned up especially concerning the LN2 shippers. It was shown that some shippers are not well protected against shocks, in consequence the overwrap or even the product bag sometimes broke. Material used for on-board transports showed fewer differences.

The chosen transport method that is very decisive. Often unattended cargo transports bear the risk that shipments are handled roughly; but it could be proved that shipping starting material unattended within an appropriate cooler works perfectly.

The right combination of transport material and transport method supplemented by project-related SOPs finally guarantees the safest and fastest result.

\section{0}

THE OPTIMIZED ORGANIZATION OF CELL THERAPY RUNS

S. Schoeffel-Weiss, M. Schmidt, H. Hanek, R. Kanakkasseri

Medical Coordination, Cellex Medical Services GmbH, Cologne, North

Rhine-Westphalia, Germany

The development during the last few years shows clearly that T-cell therapy products such as CTLP (CMV-specific T-lymphocyte precursor cells) or CAR (chimeric antigen receptor) T-cells come to the market.

During clinical phase II and III studies different partners such as GMP facilities and hospitals worldwide have to work together to produce the best outcome within the shortest possible time frame. This is only feasible with a trained medical coordination team combined with a process that schedules and controls all steps and is connected $24 / 7$ with all partners.

Ahead of a phase III study we have set up a semi-automatic workflow which is processed according to GMP guidelines combined with a computer program and an Annex 11 validated web based system.

We put an eye on the essential steps:

Confirmation request/dates

Scheduling (apheresis site, GMP facility, manufacturing site, clinical site)

Organization of necessary transport legs

Documentation flow

Dunning system

Emergency management

Controlled compliance with Chain of Identity

First we put together all aspects necessary for the complete workflow. In a second step we adapted the given necessities to a computer program to opti- mize it with the goal to receive and forward information as fast as possible. Further on the automatic notification of missing data as well as of missing documents was implemented. To make the system available for all partners worldwide a web based platform was created in addition.

The main advantages are: cascade process, data input via web based system, automatic dunning procedure concerning time and documents, one process holder.

Next we tested the complete functionality and compared the time required for a complete run with the average time that was formerly needed.

Finally the system was used during a phase III study.

It could be clearly proofed that the complete process time from collecting the starting material until delivery of the CDP can be reduced by at least $25 \%$.

201

SCALABLE EXPANSION OF HUMAN MESENCHYMAL STEM CELLS IN STIRRED-TANK BIOREACTORS

V. Dufey ${ }^{1}$, A. Tacheny ${ }^{1}$, M. Art ${ }^{1}$, J. Schouwenberg ${ }^{2}$, U. Becken ${ }^{2}$,

F. De Longueville ${ }^{1}$, M. Sha ${ }^{3}$

${ }^{1}$ Eppendorf Application Technologies, Namur, Belgium, ${ }^{2}$ Eppendorf AG

Bioprocess Center, Juelich, Germany, ${ }^{3}$ Eppendorf Inc., Enfield, Connecticut, United States

The routine application of human pluripotent and human mesenchymal stem cells (hMSCs) in cell therapy and drug discovery will require the constant supply of high cell numbers in consistent, high quality. For stem cell cultivation two dimensional systems such as T-flask are widely used, however, they are limited in terms of control and scalability. Here we present results on expansion of human bone marrow-derived mesenchymal stem cells (hMSC-BM) and human adiposederived mesenchymal stem cells (AdMSC) in rigid-wall stirred-tank bioreactors. These facilitate the precise control of critical process parameters like $\mathrm{pH}$ and dissolved oxygen, and allow a more straightforward scale up to larger process dimensions. In proof of concept studies we tested the suitability of the Eppendorf BioBLU ${ }^{\circledR}$ Single-Use Vessel portfolio for the cultivation of hMSCs. We successfully cultivated hMSCs on microcarriers, using two rigid-wall, stirredtank, single-use vessels with maximum working volumes of $250 \mathrm{~mL}$ and $3.75 \mathrm{~L}$. The cells retained their stem cell properties and their differentiation potential. Stem cell cultivation in a $3.75 \mathrm{~L}$ working volume facilitated the production of $1.6 \times 10^{9}$ cells per batch which is in the range estimated to be required per treatment dose in stem cell therapy. In summary, the presented examples demonstrate the suitability of stirred-tank, single-use bioreactors to produce clinically relevant numbers of stem cells.

202

PLURIPOTENT STEM CELL BASED MEDICINAL PRODUCTS: A CASE STUDY OF PROCESS TRANSFER RELATED TECHNICAL AND MANUFACTURING ISSUES

S. Sebastian, A. Chandra, P. Hourd, S. Wilson, M. McCall, N. Medcalf, R. Thomas, D. Williams

CBE, Loughborough University, Loughborough, Leicestershire, United Kingdom

The process transfer of a research laboratory protocol to a developer site or a manufacturing organisation is an integral part of the commercial development of a product. The manufacturing process for pluripotent cell based medicinal products has additional challenges compared to traditional pharmacological development as a consequence of the inherent biological variation of the cell lines and potential upsurge of selective cell colonies with varying genetic background. Scale-up of the research based protocols developed using multi-well microplates in to larger surface area plastic-ware further extends variability.

A recent process transfer of the human embryonic stem cell line MasterShef10 from the originator site to a manufacturing-focussed site emphasised several technical challenges. This was due to the complex nature of the cells and the requirement to further optimise the maintenance methods. An initial analysis to identify the sources of variability in the cell expansion process of different vials from a working cell bank indicated that no substantial variability arose from independently cultured vials. Further it was also determined that no significant variability arise by a single passage when the cells were cultured for 12 passages and characterised at different stages. However a major variable identified were the steps involved with passaging such as erratic post-seeding density 
and confluence during harvest. As a consequence of this, a cyclic variability in yield upon subsequent passages has occurred. Further analysis showed that the cell counting devise resulted in counting bias upon different confluence and confluence-dependent cell aggregate size. This counting bias augmented variability in seeding density and quality of post passaging survival of seeded cell colonies which caused further variability in yield.

This study points to the casual introduction of variability due to bias exists in measurement systems and the requirement for extensive process knowledge and characterisation of the process steps to determine the underlying cause of the variation. Consequently currently available cell counting methods need to be improved in order to count cells that present as aggregates. Quantitative measurements of process stages and adequately detailed Standard Operating Procedures (SOP's) will enable efficient process transfer of cell based medicinal products.

\section{3 \\ VALIDATED TRANSPORTATION SYSTEMS FOR CELL BASED PRODUCTS}

V. Segschneider, T. Rossmann-Bloeck, S. Schmalix, J. Albrecht, A. Slobodianski, $M$. Hildebrandt

TUMCells Interdisciplinary Center for Cellular Therapies, TUM School of Medicine, Munich, Bavaria, Germany

Background: With a growing interest in the development of cell based products, the need for validated transport systems suitable for temperature sensitive products grows. Conventional drug products are often designed to be stable at broad temperature ranges over a longer period of time and have been stresstested at sub-optimal conditions. Cell based products are very sensitive, so transportation should take place within a short time frame and at strictly defined temperature ranges that are suitable for the kind of cellular product to assure their functionality.

Methods: We tested and validated systems consisting of durable, isolated transportation boxes and temperature shells optimized for different temperature conditions. Our approach included systems suitable for the transportation at ranges of $<-160^{\circ} \mathrm{C}, 2-8^{\circ} \mathrm{C}, 18-25^{\circ} \mathrm{C}$ and $34-39^{\circ} \mathrm{C}$.

For temperature ranges of $2-8^{\circ} \mathrm{C}, 18-25^{\circ} \mathrm{C}$ and $34-39^{\circ} \mathrm{C}$, we relied on preconditioned temperature shells. As for frozen cells, their transportation is reportedly often performed using dry ice, reaching temperatures between -80 to $-60^{\circ} \mathrm{C}$. However, these transport systems are unsuitable for highly sensitive cells and hold a risk for the courier due to $\mathrm{CO}_{2}$ leakage. For this reason, we validated a $\mathrm{LN}_{2}$ devar system, containing the $\mathrm{LN}_{2}$ in a porous matrix, allowing the cells to reside in the vapour phase and minimizing the risk for the courier.

Results: With the preconditioned temperature shells we achieve reproducible stable temperatures for at least 64 hours in the $34-39^{\circ} \mathrm{C}$ system and 24 hours in the $2-8^{\circ} \mathrm{C}$ and $18-25^{\circ} \mathrm{C}$ systems in moderate external temperatures. With extreme external temperatures under $10^{\circ} \mathrm{C}$ and over $30^{\circ} \mathrm{C}$ the capacity of the $2-8^{\circ} \mathrm{C}$ and $18-25^{\circ} \mathrm{C}$ systems reduces to at least 12 hours, the $34-39^{\circ} \mathrm{C}$ System has not been validated for extreme temperature ranges due to extensive courier qualification. The $\mathrm{LN}_{2}$ System is stable for at least 5 days in extreme conditions, which allows the shipment to more remote places.

Conclusions: Transport systems are to be validated considering different outdoor temperatures, reproducible and narrow temperature ranges and practicability for the courier. Highly detailed packaging instructions are to be developed, to reduce handling errors.

\section{4}

QUALITY ASSURANCE OF FLOW CYTOMETRY ASSAYS: RESULTS OF THREE-YEAR SEMI-ANNUAL IMMUNE MONITORING INTERSITE COMPARISONS OF THE TCRAB-HAPLO2010 TRIAL

S. Pflitsch ${ }^{1}$, M. Schumm ${ }^{3}$, J. Rachor ${ }^{2}$, S. Karitzky ${ }^{1}$, C. Siewert ${ }^{1}$, C. Dose ${ }^{1}$

${ }^{1}$ Miltenyi Biotec GmbH, Bergisch Gladbach, Germany, ${ }^{2}$ Children's Hospital University Clinics, Würzburg, Germany, ${ }^{3}$ Children's University Hospital, Tübingen, Germany

Since cellular, immune and gene therapy are evolving and promising medical fields in research and daily routine, immune monitoring has become an essential tool for determining treatment-induced effects on immune cells. Flow cytometry offers the opportunity to monitor immunological parameters in clinical trials on low amounts of cellular material (e.g. whole blood) with a reasonable amount of time. However, reproducibility of flow cytometry-based immune monitoring is a matter of high importance, especially when multiple sites are involved. Here we present results of the semi-annual inter-site comparisons conducted over 3 years as a quality assurance measure of flow cytometry-based immune monitoring for the TCRab-Haplo2010 trial. To assess the reproducibility of the immune monitoring in different flow cytometry core labs, blood from a healthy donor was centrally collected and distributed to the participating labs. Samples were assayed within 25 to 30 hours after blood collection by four operators using four different MACSQuant Analyzer devices at three different sites. Immune cell subsets, which are relevant to evaluate immune reconstitution after haploidentical hematopoietic stem cell transplantation with TCR $\alpha \beta-C D 19$ depleted stem cell grafts ( $\mathrm{T}$ cells, T helper cells, cytotoxic T cells, B cells, NK cells, TCR $\alpha \beta^{+}$and TCR $\gamma \delta^{+}$T cells) showed an average coefficient of variation (CV) of $6.28 \%( \pm 3.89 \%)$ for percentage of subsets among CD45 $5^{+}$cells and of $9.13 \%( \pm 5.48 \%)$ for cells/ $\mu$ l (two platform approach). These inter-site comparisons over a period of 3 years demonstrated low variability of immune monitoring results and thereby confirm reliability and comparability of patient immune monitoring data obtained in the TCRab-Haplo2010 flow cytometry core labs.

205

RAPID AND ROBUST LARGE-SCALE EXPANSION OF HIGH QUALITY HUMAN MESENCHYMAL STEM CELLS FOR USE IN REGENERATIVE MEDICINE APPLICATIONS

D. Splan ${ }^{1}$, L. Lock ${ }^{2}$, J.A. Rowley ${ }^{2}$, M.S. Szczypka ${ }^{1}$

${ }^{1}$ Single Use Technologies, Pall Life Sciences, Ann Arbor, Michigan, United States, ${ }^{2}$ RoosterBio, Frederick, Maryland, United States

Human mesenchymal stem cells (hMSC) isolated from various tissues represent the most highly utilized cell type for cell therapy and regenerative medicine applications. However, a major impediment to progress in the field is availability of sufficient numbers of high quality hMSC for process development studies. Given that large numbers of high quality cells are required for many applications and that large surface area requirement for cell expansion is necessary, a search for a practical manufacturing platform for hMSC expansion has been ongoing over the last decade. Feasibility studies have established the utility of using microcarriers in dynamic cultures for expansion of hMSC and the results have positioned this technology as the platform of choice for the costeffective generation of hMSC. Microcarrier cultures performed in fully closed single-use systems provide a platform for cell expansion and are a logical extension of traditional manufacturing technologies.

We have developed a rapid and robust manufacturing platform that enables reproducible expansion of large numbers of high quality hMSC from fedbatch microcarrier cultures without the need for media exchanges or extensive process development. Studies with bone marrow-derived hMSC using sterile microcarriers in single-use bioreactors reproducibly generated over twentyfold expansion in $6 \mathrm{~L} \mathrm{PadReactor}{ }^{\circledast}$ Mini bioreactors in 4 days. Cryopreserved Allegro $^{\mathrm{TM}}$ Unison hMSC seeded directly onto SoloHill microcarriers in the PadReactor Mini bioreactor followed by transfer of cells to a larger volume PadReactor system showed $>200$-fold expansion in only 8 days. Cells expanded using this platform and processes maintain critical quality and functional attributes. This single-use system along with the processes developed in these studies is ready for use by others to generate billions of cells without the need for further development.

\section{6}

SIMPLE AND EFFICIENT CELL HARVEST METHODS FOR MICROCARRIER CULTURES IN BIOREACTORS

\section{G. Patel, J. Liu, D. Splan, M.S. Szczypka}

Single Use Technologies, Pall Life Sciences, Ann Arbor, Michigan, United States

The realization of cell therapies and regenerative medicine applications is dependent upon development of cost-effect, robust and reproducible technologies for generation of high quality cells. Microcarriers employed in single-use bioreactors provide a robust and reproducible system for cell expansion; however, efficient use of microcarriers for this purpose requires a scalable cell harvest process. Pall SoloHill microcarriers are rigid spheres that support rapid and efficient cell attachment and subsequent cell growth in bioreactors. These physical characteristics also allow users to employ standard cell culture harvest methods for detachment and separation of cells from microcarriers but techniques used 